\title{
Impact of Piriformospora indica, Pseudomonas species and Mesorhizobium cicer on growth of chickpea (Cicer arietinum L.)
}

\author{
Pallavi Mansotra ${ }^{*}$, Poonam Sharma $^{1}$, Asmita Sirari ${ }^{1}$ and Sunita Sharma ${ }^{1}$ \\ *Department of Microbiology, Punjab Agricultural University, Ludhiana -141 004 (Punjab), INDIA \\ ${ }^{1}$ Department of Plant Breeding and Genetics, Punjab Agricultural University, Ludhiana- 141004 (Punjab), INDIA \\ *Corresponding author. E-mail: pallavi-cobsmb@pau.edu
}

Received: January 20, 2015; Revised received: April 11, 2015; Accepted: May 12, 2015

\begin{abstract}
The present study was conducted to examine synergistic interactions among Piriformospora indica (PI) with potential plant growth promoting rhizobacteria (PGPR) and Mesorhizobium cicer (LGR33, MR) in two chickpea (Cicer arietinum L.) varieties viz. desi PBG1 and kabuli BG1053. Different PGPR species were used viz. native isolates of Pseudomonas argentinensis (LPGPR1), Pseudomonas sp. (LPGPR2) along with national check Pseudomonas sp. (LK884). Compatibility of MR, PI and different Pseudomonas spp. was studied by streak assay method and growth of fungal pellicle in-vitro. Consortium of MR+PI+LPGPR1 $(0.605 \mathrm{~g}$ dry weight fungal pellicle/100ml nutrient broth) was found as the best compatible treatment. In-vivo the synergistic effect of consortia was studied for improving dry weight of roots, nutrient acquisition, colonization and stress tolerance ability in chickpea. Significant improvement in dry weight of root was observed with MR+PI+LPGPR1 (1.316 $\mathrm{g} \mathrm{plant}^{-1}$ ) in comparison to MR alone treatment $\left(0.980 \mathrm{~g} \mathrm{plant}^{-1}\right)$ at 90 days after sowing (DAS). Percentage colonization of $P$.indica improved significantly with consortium MR+PI+LPGPR1 $(75.5$ and $78.3 \%)$ treatment at 90 DAS. All the treatments significantly improved total soluble sugar content (12.2-26.9\%); amino $\mathrm{N}$ content (1.36-1.80 fold) and stress tolerance ability (4-6 fold) over the MR alone treatment. Reducing sugar content significantly improved with MR+PI+LPGPR1 (0.62 and $\left.0.79 \mathrm{mg} \mathrm{mL}^{-1}\right)$ over MR alone $\left(0.42\right.$ and $\left.0.58 \mathrm{mg} \mathrm{mL}^{-1}\right)$ treatment in desi PBG1 and kabuli BG1053 chickpea, respectively. The tripartite combination MR+LPGPR1+PI can be explored as potent biofertilizer for improvment in chickpea productivity.
\end{abstract}

Keywords: Chickpea, Mesorhizobium cicer, Multipartite interactions, Piriformospora indica, Pseudomonas species

\section{INTRODUCTION}

Chickpea (Cicer arietinum L.) is an important draught-tolerant food legume in the world. Chickpea being a symbiotic crop establishes a cooperative association with bacterium Mesorhizobium of family Rhizobiacea to fulfill its nitrogen $(\mathrm{N})$ requirements and fixes about $141 \mathrm{Kg} \mathrm{ha}^{-1}$ $\mathrm{yr}^{-1}$ molecular N (Singh, 2014). The success of rhizobial inoculation on plant roots is limited by several factors, including environmental conditions, number of infective cells applied, presence of competitive native rhizobia and inoculation method (Jida and Assefa, 2012). The native rhizobia often have nutritional competitive advantage over the inoculated strains which fail to ensure effective nodulation and adequate Biological Nitrogen Fixation (BNF). One of the strategies to increase survival and establishment of inoculated Mesorhizobium sp. in soil environment is to integrate it with other plant growth promoting rhizobacteria (PGPR). PGPR are known to improve plant growth by direct and indirect mechanisms (Bashan and de-Bashan 2010). Recently, co-inoculation of Mesorhizobium sp. with Pseudomonas aeruginosa was reported to significantly increase the nodulation, plant growth and yield in chickpea. (Verma et al., 2013). Piriformospora indica, belongs to the order
Sebacinales including mostly endophytic fungi with cryptic biodiversity (Oberwinkler et al., 2013). P. indica helps in mobilization of insoluble phosphates (Varma et al., 1999) and also provides protection against biotic and abiotic stress including root and leaf pathogens (Johnson et al., 2014), enhances seed production and stimulates active ingredients in plants allowing plants to grow under extreme physical and nutrient conditions (Danesh, 2015). Co-inoculation of $P$. indica with PGPR (Pseudomonas striata) was found to have synergistic effect on its population build up and plant dry biomass with respect to single inoculation in chickpea (Meena et al., 2010). Recently there is emerging trend on application of binary and multiple mixtures of microbes for improving plant productivity. Beneficial micro-organisms have the potential to reduce the dependence on chemicals, increase resistance to biotic and abiotic stress while still maintaining productivity of crop (Mishra et al., 2014). Therefore, the present study was designed to investigate compatibility of $P$. indica with PGPR and Mesorhizobium in-vitro and assess the synergistic effect of this tripartite mixture for plant growth promotion, percentage colonization, nutrient acquisition and stress tolerance in chickpea. 


\section{MATERIALS AND METHODS}

Procurement of Reference cultures: Mesorhizobium cicer (LGR33, MR) used in the present study was procured from Pulses Microbiology Laboratory, Department of Plant Breeding and Genetics, Punjab Agricultural University (PAU), Ludhiana and maintained on Yeast Extract Mannitol Agar (YEMA) medium. Reference strain of PGPR (Pseudomonas sp. LK884) was procured from GB Pant University of Agricultural and Technology, Uttarakhand and native strains of PGPR isolated from chickpea rhizosphere viz. Pseudomonas argentinensis (LPGPR1) and Pseudomonas sp. (LPGPR2) were procured from Pulses section, Department of Plant Breeding and Genetics, Punjab Agricultural University (PAU), Ludhiana and were maintained on King's B medium. Fungus Piriformospora indica (PI) was procured from Department of Microbiology, Chaudhary Charan Singh Haryana Agricultural University (CCSHAU), Hisar and was subcultured on Potato dextrose agar (PDA) medium and stored at $4^{\circ} \mathrm{C}$ in refrigerator.

Compatibility of $P$.indica with different PGPR and Mesorhizobium: Compatibility of P.indica with different Pseudomonas spp. (LPGPR1, LPGPR2 and LK884 (reference)) along with recommended strain of Mesorhizobium cicer (LGR33) was examined in-vitro by streak assay method (Raja et al., 2006) and on the basis of growth of fungal pellicle. A small block of agar (PDA) with fungal growth was cut using sterile cork borer, placed in the centre of fresh nutrient agar plate and kept as control. In streak assay, different Pseudomonas strains (LPGPR1, LPGPR2 and LK884) were streaked on one side of fungal bit with LGR33 on the opposite side and allowed to incubate at $25 \pm 2^{\circ} \mathrm{C}$ for 3-5 days. Each treatment had three replications with one control plate with small block of agar with fungal growth. For examining growth of fungal pellicle fresh inoculum of Mesorhizobium cicer (LGR33) was prepared by growing in Yeast Extract Mannitol Broth (YEMB) whereas different Pseudomonas species (LPGPR1, LPGPR2 and LK884) were grown in Luria broth for 24-48 hrs. $P$. indica was raised in PDA medium. One $\mathrm{ml}$ inoculum of each organism was then transferred to $100 \mathrm{ml}$ nutrient broth in separate $250 \mathrm{~mL}$ conical flask in triplicate, with different PGPR combinations. The inoculated cultures were incubated at $25 \pm 2{ }^{\circ} \mathrm{C}$ in rotary shaker for $6-8$ days. Fungal pellicle was dried in hot air oven at $60^{\circ} \mathrm{C}$ and weight was recorded.

Cultivation of chickpea: Field experiment was conducted in rabi season (2011-12) at Pulses Research Farm, Department of Plant Breeding and Genetics, Punjab Agricultural University, Ludhiana. The pooled mean of maximum and minimum temperature during crop growth period was $23.9^{\circ} \mathrm{C}$ and $9.3^{\circ} \mathrm{C}$, respectively. Experimental soil was loamy sand having $\mathrm{pH}(8.2)$ with low organic carbon $(0.12 \%)$ and available $\mathrm{N}$ $\left(92.0 \mathrm{~kg}\right.$ acre $\left.^{-1}\right)$, medium available P (18.4 kg acre $\left.{ }^{-1}\right)$ and high available $\mathrm{K}\left(105 \mathrm{~kg} \mathrm{acre}^{-1}\right)$. Chickpea seeds of varieties desi (PBG1) and kabuli (BG1053) were procured from the Pulses Section, Department of Plant Breeding and Genetics, PAU, Ludhiana. Seeds were applied at the rate of $18-20 \mathrm{~kg} \mathrm{acre}^{-1}$ for desi and 35-37 $\mathrm{kg}$ acre $^{-1}$ for kabuli for sowing. Experiment was designed in factorial randomized block design (FRBD) with 36 plots and 8 rows having row to row distance of $30 \mathrm{~cm}$ and plant to plant distance about $10 \mathrm{~cm}$ with net plot size 5.4 sq.m. Seeds were inoculated with recommended cultures of MR, PI and different PGPR spp. (LK884, LPGPR1 and LPGPR2) as per treatment. Twenty gram charcoal inoculants were used per $\mathrm{kg}$ of chickpea seeds for inoculation in monoculture treatment. In co-inoculation treatments, Mesorhizobium cicer, P.indica and different PGPR strains were applied to chickpea seeds in ratio of 1:1:1. Before sowing, inoculated seeds were air dried at room temperature under shade and sown with in two hours. Each treatment had three replications. All the agronomic practices were followed for raising chickpea crop.

Dry weight of root: Roots of three randomly selected plants were uprooted at 60 and 90 DAS from each plot and dry weight of root was recorded in $\mathrm{g}$.

Root colonization studies: The observations were recorded on percentage colonization of P.indica at 90 and 120 DAS by randomly selecting 5-10 root samples from the chickpea root. Colonization was studied by staining roots with trypan blue (Phillips and Hayman, 1970). The stained root sections were studied under microscope (Leica type 020-518.500) for the presence of hyphae, vesicles and spores. The percentage colonization was calculated for the inoculated plants according to following formula:

$\%$ Infection $=$ (no of fungus infection segments/Total no segments examined) 100

Collection of root exudates: Frozen root tissues were homogenized at $4{ }^{\circ} \mathrm{C}$ in an ice-chilled mortar in QB buffer (Kumar et al., 2009). Crude homogenates were centrifuged at $15000 \mathrm{~g}$ for $15 \mathrm{~min}$ at $4{ }^{\circ} \mathrm{C}$, and the supernatant fractions were frozen at $-20{ }^{\circ} \mathrm{C}$. Data on various plant biochemical parameters viz. total soluble and reducing sugars, amino $\mathrm{N}$ content and antioxidant enzyme activities viz. superoxide dismutase (SOD) and catalase (CAT) activities were analyzed at 90 and120 DAS, respectively.

Analysis of plant biochemical parameters: Root exudates from different treatments were collected at 90 DAS and studied for total soluble and reducing sugars and amino nitrogen content. Total soluble sugars (TSS) of root exudates from different treatments were assayed spectrophotometrically at $490 \mathrm{~nm}$ (DuBois et al., 1956) using $5 \%$ phenol reagent followed by concentrated sulphuric acid $\left(\mathrm{H}_{2} \mathrm{SO}_{4}\right)$. For analyzing reducing sugars, root exudates from different treatments $(0.1 \mathrm{~mL})$ were subjected to reaction with Nelson's arsenomolybdate reagent (Somogyi, 1952). The absorbance of clear solution was read at $620 \mathrm{~nm}$ 
using UV-Vis spectrophotometer. Amino N content of root exudates of different treatments was determined by using ninhydrin reagent at $570 \mathrm{~nm}$ (Moore and Stein, 1948)

Antioxidant enzyme activities: Antioxidant enzymes activities viz. Catalase (CAT) and Superoxide dismutase (SOD) activities of root exudates from different treatments were recorded at 120 DAS.

Catalase (CAT) activity: The catalase activity of root exudates was calculated on the basis of micromoles of hydrogen peroxide $\left(\mathrm{H}_{2} \mathrm{O}_{2}\right)$ oxidized per minute per $\mathrm{g}$ fresh weight of root tissue extracted with phosphate buffer (Aebi, 1983).

Superoxide dismutase (SOD) activity: For SOD activity, the root exudates were treated with Tris- $\mathrm{HCl}$ buffer, EDTA and pyragallol solution (Marklund and Marklund, 1974). A unit of enzyme activity had been defined as amount of enzyme causing 50\% inhibition of auto-oxidation of pyragallol observed in blank.

Statistical analysis: The data was analyzed using analysis of variance (ANOVA). Critical difference (CD) at 5\% percent level was calculated. Further mean separation of treatment effects was accomplished using Tukey's Honestly Significant Difference Test. All the data analysis was carried out using SAS software (Slaughter and Delwiche, 2010) using Factorial Randomized Block Design.

\section{RESULTS AND DISCUSSION}

Compatibility of $P$. indica with different PGPR (LPGPR1, LPGPR2 and LK884) along with Mesorhizobium cicer (MR) in streak assay method revealed that $P$. indica and Mesorhizobium showed better

compatibility with LPGPR1 and LK884 in comparison to LPGPR2 (Plate 1). In the present study, synergistic effect of Mesorhizobium cicer, P.indica and different PGPR enhanced the growth of fungal pellicle (P.indica). Maximum dry weight of fungal pellicle was observed with the consortium of MR+PI+LPGPR1 $\left(0.605 \mathrm{~g}\right.$ dry weight fungal pellicle $100 \mathrm{~mL}^{-1}$ nutrient broth) followed by MR+PI+LK884 (0.591 g dry weight fungal pellicle $100 \mathrm{~mL}^{-1}$ nutrient broth) and MR+PI+LPGPR2 (0.578 g dry weight fungal pellicle $100 \mathrm{~mL}^{-1}$ nutrient broth) as compared to the P.indica alone $\left(0.515 \mathrm{~g}\right.$ dry weight fungal pellicle $100 \mathrm{~mL}^{-1}$ nutrient broth) (Fig.1). Indole acetic acid (IAA) is best known for its role in plant signal transduction (Ghosh et al., 2013). Mesorhizobium cicer and LPGPR1 used in the present study are known to produce IAA (Kaur and Sharma, 2013). However, this hormone can act as a signal molecule in bacteria and fungi (Leveau and Preston, 2008) and was also found to induce adhesion and filamentation of Saccharomyces cerevisia (Prusty et al., 2004). Therefore, IAA produced by PGPR and Mesorhizobium cicer might have induced filamentation and increased dry weight of the fungal pellicle.

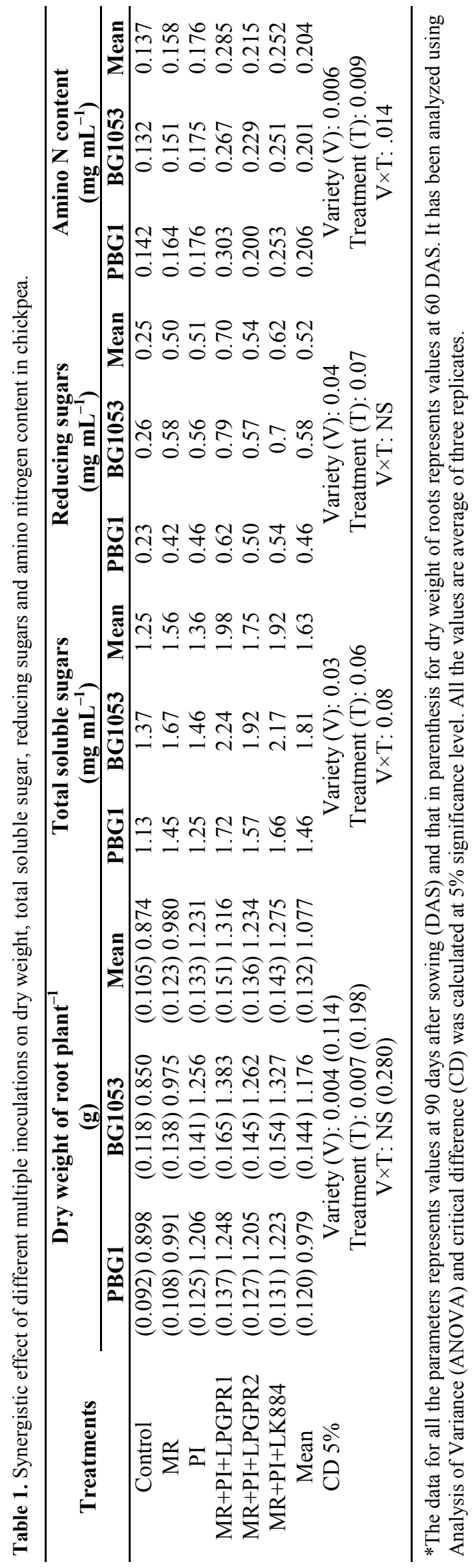




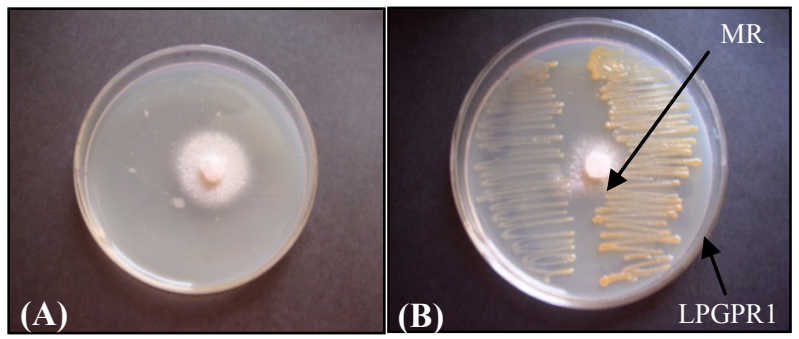

Plate 1. Compatibility of P.indica with Mesorhizobium cicer along with P. argentinensis (LPGPR1). (A) Control (P.indica); (B) $M R+P I+L P G P R 1$

The data in Table 1 recorded significant improvement in dry weight of root at 60 and 90 DAS with multiple inoculations of Mesorhizobium cicer, P.indica and different PGPR as compared to Mesorhizobium cicer alone treatment. There was significant $(P<0.05)$ difference between the varieties for dry weight of root; however interaction between variety and treatment was significant at 90 DAS. Mean of both the varieties at 60 DAS revealed that multiple inoculation of MR+PI+LPGPR1 showed maximum increase in root dry weight $\left(0.151 \mathrm{~g} \mathrm{plant^{-1 } )}\right.$ (Meena et al., 2010) followed by $\mathrm{MR}+\mathrm{PI}+\mathrm{LK} 884 \quad\left(0.143\right.$ gplant $\left.^{-1}\right)$ and $\mathrm{MR}+\mathrm{PI}+\mathrm{PGPR} 2\left(0.136 \mathrm{~g} \mathrm{plant}^{-1}\right)$. At 90 DAS significant increase in dry weight of root was observed in MR+PI+LPGPR1 (1.316 $\left.\mathrm{g} \mathrm{plant}^{-1}\right)$ followed by MR+PI+LK884 (1.275 g plant $\left.^{-1}\right)$ and MR+PI+PGPR2 $\left(1.234 \mathrm{~g} \mathrm{plant}^{-1}\right)$ treatments $(P<0.05)$. These results are corroborated with the earlier findings reporting that co-inoculation of the endophytic fungus P.indica with the phosphate-solubilising bacterium P.striata significantly increased dry plant biomass in comparison to treatment with single inoculation and non-inoculated control in chickpea (Meena et al., 2010). Moreover, co -inoculation of the PGPR (Pseudomonas and Bacillus) with effective Rhizobium strains of chickpea resulted in a significant improvement in the growth parameters (Parmar and Dadarwal, 1999). It was further supported by investigation in Arabidopsis where $P$. indica formed intracellular structures in the epidermal root cells and caused changes in the root growth, leading to branched root systems (Sirrenberg et al., 2007). Since the fungus also releases auxin in the culture medium and thus affecting root growth which is responsible for, or at least contributes to, the beneficial interaction between the two symbionts (Oelmuller et al., 2009).

P.indica successfully colonizes roots of chickpea plants with hyphal growth of chlamydospores (Plate 2) showing balanced symbiotic relationship (Murphy et al 2013). Data on percent colonization (Figs. $2 \mathrm{a}$ and b) revealed that all the multiple inoculations P.indica treatments varied significantly over control and MR alone treatment (90 and 120 DAS). At 90 DAS significantly higher colonization percentage was found in MR+PI+LPGPR1 (75.5 and $78.3 \%)$ followed by $\mathrm{MR}+\mathrm{PI}+\mathrm{LK} 884(70.7$ and $73.3 \%)$ and MR+PI+LPGPR2 (57.7and 55.7\%) in desi PBG1 and kabuli BG1053 chickpea, respectively $(P<0.05)$. In uninoculated control

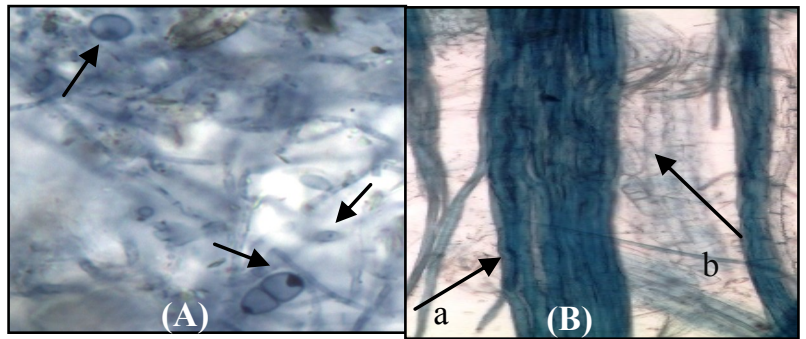

Plate 2. Intracellular root colonization of $P$. indica in chickpea (A) Chlamydospores (black arrows) (B) Hyphae of P.indica (black arrow a) and root cells (black arrow b)

plots native fungal (Glomus sp.) colonization was 38.3 and $30.3 \%$, whereas in MR alone treatment 43 and $40.3 \%$ colonization recorded in desi PBG1 and kabuli BG1053 chickpea, respectively. This colonization revealed the infective potential of both the native mycorrhiza present in the legume rhizosphere along with inoculated P.indica. At 120 DAS maximum colonization percentage was found in MR+PI+PGPR1 $(60.7 \%$ and $61.7 \%$ ) followed by MR+PI+LK884 (ranged between $58.3 \%$ and $60.3 \%$ ). A positive influence of root colonization with P.indica treatments on vegetative growth and development in chickpea plants was observed in present study. Our study is well in line with Bagde et al., (2010) for Spilanthes calva and Withania somnifera where P.indica treated plants showed pronounced root colonization and growth relative to non-inoculated control . Similarly, it was demonstrated that root colonization of Adhota vasica by P.indica increased with time from 53 to $95 \%$ (Rai et al., 2001). There was remarkable enhancement in the growth rate of plant inoculated with P.indica over the control so it is reasonable to assume that beneficial interaction between host plant and P.indica is dependent on the size and surface of the root, which can be colonized by fungus (Oelmuller et al., 2009). However, this was in disagreement with the earlier work where root colonization of the Arabidopsis (tf12) mutant having dwarf phenotype and small root surface is strongly reduced due to reduced auxin and glucosinolate level (Bennett et al., 2005). Colonization is a time dependent phenomenon

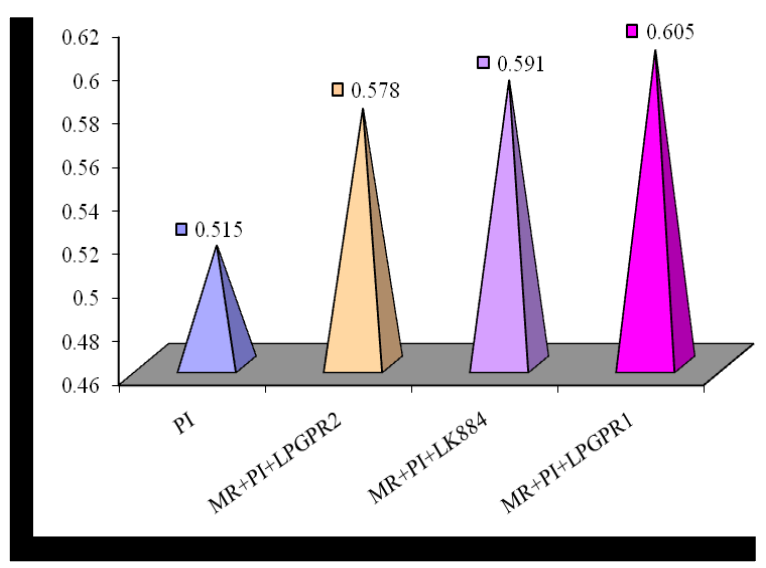

Fig.1. Synergistic effect of different multiple inoculations on dry weight of fungal pellicle in chickpea. 

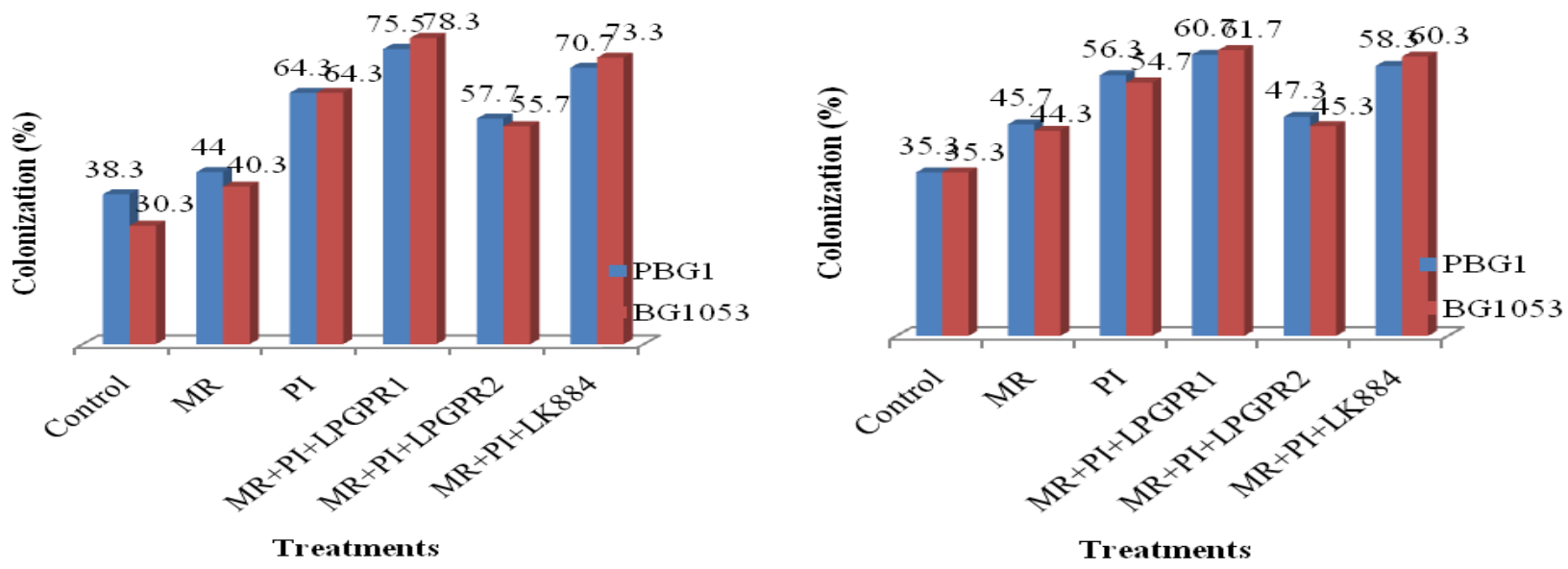

Fig. 2. Synergistic effect of different multiple inoculations on P. indica colonization (90 and 120 DAS).

affected by several factors as light, moisture, host genotype, age of host plant, nutrient deficiency (Badri and Vivanco, 2009). However, in present study P.indica colonization further showed decreasing trend towards crop maturity stage. It was related to limited carbohydrate availability, as a consequence of a decline in photosynthesis due to mobilization of the reserves towards the pod formation and also due to qualitative and quantitative changes in the root exudate towards the root senescence (Haichar et al., 2014). However, colonization in MR alone showed improvement over the control. Mesorhizobium cicer could have acted synergistically on the growth of native mycorrhiza. Our results are well supported by the study that inoculation with Rhizobium significantly increased root colonization by native mycorrhizal fungi and spore numbers in soil in lentil (Lakshman and Kadam, 2011). There was increase in the percent colonization in all the multiple inoculations and also the PI alone as compared to the MR alone treatment. Moreover, the colonization percentage was significantly higher in MR+PI+LPGPR1 followed by MR+PI+LK884 over the PI alone treatment at 90 and 120 DAS $(P<0.05)$. It is well documented that highest mycorrhizal colonization percentage was found in plants inoculated with the AMF and B.coagulans suggested a possible mechanism of PGPR due to hydrolytic enzymes which caused the cortical cells to dilate, provided a larger intercellular surface area for AMF to penetrate and colonize more easily (Mamatha et al., 2002). This study well corroborates with our results. Similarly, PGPR-Azospirillum brasilense with production of IAA stimulated mycorrhizal colonization of Glomus deserticola in maize and enhanced spore germination and mycelial growth, which in turn increased the chance of contact between fungal hyphae and plant roots (Sharma et al., 2008).

Variation in total soluble sugar, reducing sugar and amino $\mathrm{N}$ content was recorded in desi and kabuli chickpea varieties (Table 1). It is well documented that root exudation rates also vary with developmental stage of plant and between genotypes within single species (Inceoglu et al., 2010 and Haichar et al., 2014). The data in table 1 depicts that all the treatments significantly improved total soluble sugars as compared to uninoculated control treatment at 90 DAS $(P<0.05)$. On the basis of pooled mean, MR+PI+LPGPR1 treatment significantly improved total soluble sugar content in the range of 12.2-26.9\% over the Mesorhizobium cicer alone treatment followed by MR+PI+LK884 and MR+PI+LPGPR2. Variety BG1053 recorded significantly high amount of total soluble sugars as compared to variety PBG 1. Significant improvement in the reducing sugars was recorded with $\mathrm{MR}+\mathrm{PI}+\mathrm{LPGPR} 1 \quad(0.62$ and $0.79 \mathrm{mg}$

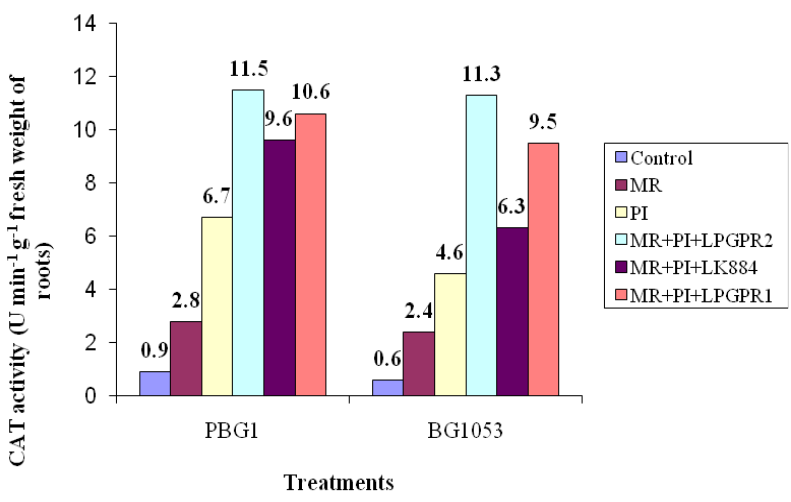

Fig. 3. Synergistic effect of different multiple inoculations on CAT activity.

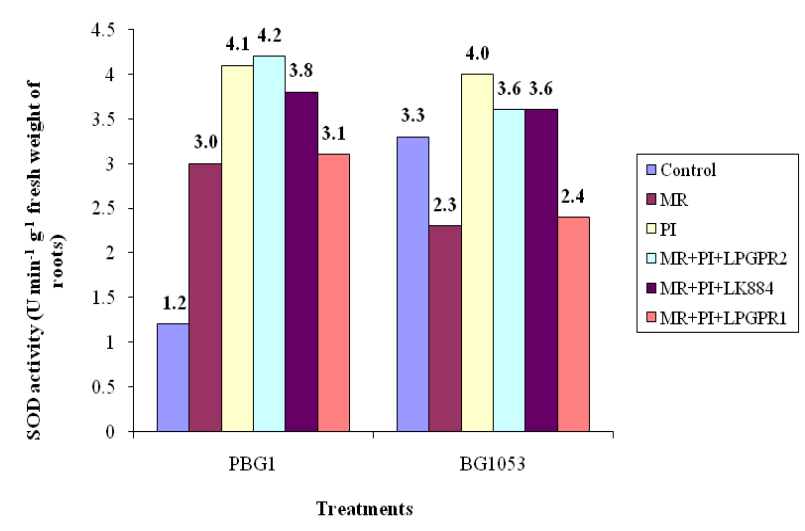

Fig. 4. Synergistic effect of different mutiple inoculations on SOD activity. 
$\left.\mathrm{mL}^{-1}\right)$ and $\mathrm{MR}+\mathrm{PI}+\mathrm{LK} 884\left(0.54\right.$ and $\left.0.70 \mathrm{mg} \mathrm{mL}^{-1}\right)$ treatments while the difference was non-significant with MR+PI+LPGPR2 treatment. Chickpea variety kabuli BG1053 yielded significantly high reducing sugars as compared to desi PBG1. On the basis of mean of two varieties, all the multiple inoculation treatments showed significant improvement in amino $\mathrm{N}$ content ranging from 1.36-1.80 fold. Multiple inoculants have brought considerable change in the root exudates content. In single inoculation less amount of total sugars, reducing sugars and amino nitrogen content was detected. Total sugars, reducing sugars and amino nitrogen content in the consortium applied treatments were higher than in individual inoculant applied treatments. High root exudation in multiple inoculant treatments might have positively correlated with root growth which stimulated the actively growing root system to secrete more root exudates (Garcia et al., 2001). It is also well documented that the total soluble sugars, reducing sugars and amino nitrogen content were higher with use of bio-inoculant consortium of Azospirillum lipoferum with PGPR (Pseudomonas fluorescens and Bacillus megaterium) in the rice root exudates than in individual inoculant applied treatments (Raja et al., 2006).

Data in fig. 3 depicted effect of different tripartite inoculations on catalase activity at 120 DAS. Difference for the catalase activity (CAT) between chickpea varieties, among different treatments and interaction between varieties and treatments over control was significant $(P<0.05)$. On the basis of mean of two chickpea varieties, CAT activity in PI alone treatment was $5.7 \mathrm{U} \mathrm{min}^{-1} \mathrm{~g}^{-1}$ fresh weight of roots which was higher than MR alone treatment $\left(2.6 \mathrm{~min}^{-1}\right.$ $\mathrm{g}^{-1}$ fresh weight of roots). Further, all the multiple inoculated treatments improved stress tolerance ability ranged from 4-6 fold over the Mesorhizobium cicer alone treatment. Catalase activity was significantly high in MR+PI+LPGPR1 treatment (11.5 $\mathrm{U} \mathrm{min}^{-1} \mathrm{~g}^{-1}$ fresh weight of roots in desi PBG1 and $11.3 \mathrm{~min}^{-1} \mathrm{~g}^{-1}$ fresh weight of roots in kabuli BG1053 $\mathrm{U} \mathrm{min}^{-1} \mathrm{~g}^{-1}$ fresh weight of roots). Improved CAT activity in PI alone and multiple inoculant treatment in present study can be explained as P.indica symbiosis promoted plant growth during abiotic stress. Similarly, 77-fold increase in CAT activity in R.trifolii during water stress has been reported earlier (Goyal et al., 1986). Similarly CAT activity reduced draught stress in chickpea with Mesorhizobium inoculation (Esfahani et al., 2010) and used it as biochemical marker of BNF (Mhadhbi et al., 2004). One of the earlier studies also revealed that draught stress induced a range of physiological and biochemical responses in plants such as stomatal closure and repression of photosynthesis (Varma et al., 1998). As at 120 DAS the maximum temperature was $35.1^{\circ} \mathrm{C}$ in the month of April and all the P.indica treated plants induced higher CAT activity and might have promoted draught tolerance. Similarly, higher
CAT activity was recorded in root and shoot parts in Chinese cabbage (Sun et al., 2010), maize (Kumar et al., 2009) and barley (Baltruschat et al., 2008). The root-colonizing fungal mutualist $P$.indica was discovered in association with the roots of woody shrubs in the Indian Thar desert (Varma et al., 1999) suggesting that the fungus may confer fitness benefits under draught-stress conditions. Antioxidant enzymes are known to play an important role in P.indica symbiosis conferring abiotic stress tolerance (Sartipnia et al., 2013). It was also studied that $P$. indica conveys better tolerance to various abiotic and biotic stresses as well as improved fitness to host plant through colonization (Qiang et al., 2014). Data for superoxide dismutase (SOD) activity for different tripartite inoculations at 120 DAS (Fig.4) revealed significant difference with all the treatments except control $(P<0.05)$. SOD activity in P.indica alone treatment (4.1 $\mathrm{U} \mathrm{min}^{-1} \mathrm{~g}^{-1}$ fresh weight of roots) was found higher than MR alone treatment $(2.7 \mathrm{U}$ $\mathrm{min}^{-1} \mathrm{~g}^{-1}$ fresh weight of roots) on the basis of mean of both chickpea varieties. Further all the multiple inoculant treatments showed improved stress tolerance ability over the Mesorhizobium cicer alone treatment. Maximum SOD activity was found in MR+PI+LPGPR1 treatment which was 4.2 and $3.6 \mathrm{U} \mathrm{min}^{-1} \mathrm{~g}^{-1}$ fresh weight of roots in kabuli BG1053and desi PBG1, respectively. Increased level of SOD (antioxidant enzymes) in PI alone and multiple inoculation treatments during the colonization period might have resulted in detoxification of ROS and played a protective role in interaction of plant and fungi (Singh et al., 2011). Our findings are well in line with Kumar et al.( 2009) who reported enhanced SOD activity in maize roots colonized with $P$. indica. In multiple inoculant treatment root endophytes might have acted as a biological mediator allowing symbiotic plants to activate stress response system more efficiently than uninoculated control plants (Bharadwaj et al., 2008).

\section{Conclusion}

This study indicated the compatibility of Mesorhizobium cicer and P.indica with different PGPR in-vitro as well as in-vivo revealed positive effects on chickpea through amino $\mathrm{N}$-content, total soluble and reducing sugars and $P$. indica colonization. Bioaugmentaion of tripartite inoculant (LPGPR1 with MR and PI) can be explored as potent biofertilizer in chickpea.

\section{REFERENCES}

Aebi, H. E. (1983). Catalase. In: Bergmeyer HO (ed) Methods of Enzymatic Analysis Academic. Vol III, pp 273-86. Acad Press, New York.

Badri, D. V. and Vivanco, J. M. (2009). Regulation and function of root exudates. Plant Cell. Envir., 32: 666-68.

Bagde, U. S., Prasad, R. and Varma, A. (2010). Interaction of Mycobiont: Piriformospora indica with medicinal plants and plants of economic importance. Afr. J. Biotechnol., 9(54): 9214-26.

Baltruschat, H., Fodor, J., Harrach, B.D., Niemczyk, E., Barna, B. and Gullner, G. (2008). Salt tolerance of barley 
induced by the root endophyte Piriformospora indica is associated with a strong increase in antioxidants. New Phytol., 180: 501-10.

Bashan, Y. and de-Bashan, L.E. (2010). How the plant growth-promoting bacterium Azospirillum promotes plant growth-a critical assessment. Adv. Agron., 108: 77 -136 .

Bennett, R.N., Wenke, T., Freudenberg, B., Mellon, F.A. and Ludwig-Müller, J. (2005). The tu8 mutation of Arabidopsis thaliana encoding a heterochromatin protein 1 homolog causes defects in the induction of secondary metabolite biosynthesis. Plant Biol., 4: 348-357.

Bharadwaj, D.P., Lundquist, P.O. and Alstrom, S. (2008). Arbuscular mycorrhizal fungal spore-associated bacteria affect mycorrhizal colonization, plant growth and potato pathogens. Soil. Biol. Biochem., 40(1): 2494-01.

Danesh, Y.R., (2015). The Piriformospora indica, magic fungus and its role on sustainable agriculture. J. Agric. Technol., 11(2): 517-523.

DuBois, M., Gilles, K. A., Hamilton, J.K., Rebers, P.A. and Smith, F. (1956). Colorimetric method for determination of sugars and related substances. Anal. Chem. 28(3): 350-56.

Esfahani, M.N., Mostajeran, A. and Emtiazi, G. (2010). The effect of draught stress on nitrogenase and antioxidant enzyme activities in nodules formed from symbiosis of chickpea with two strains of Mesorhizobium ciceri. World J. Sci., 10(6): 621-26.

Garcia de Salamone, I.E., Hynes, R.K. and Nelson, L.M. (2001). Cytokinin production by plant growth promoting rhizobacteria and selected mutants. Can. J. Microbiol., 47: 404-11.

Ghosh, P.K., Saha, P., Mayilraj, S. and Maiti, T.K. (2013). Role of IAA metabolizing enzymes on production of IAA in root, nodule of Cajanus cajan and its PGP Rhizobium sp. Biocatalysis Agric. Biotechnol., 2:234-239.

Goyal, V., Chetal, S. and Nainawatee, H. S. (1986). Alterations in Rhizobium trifolii catalase under water stress. Folia. Microbiol., 31: 164-66.

Haichar, F.Z., Santaella, C., Heulin, T. and Achouak, W. (2014). Root exudates mediated interactions belowground. Soil. Biol. Biochem., 77: 69-80.

Inceoglu, O., Salles, J.F., Overbeek, L.V., and Elsas, J.D. (2010). Effects of plant genotype and growth stage on the betaproteobacterial communities associated with different potato cultivars in two fields. Appl. Environ. Microbiol., 76: 3675-3684.

Jida, M. and Assefa, F. (2012). Phenotypic diversity and plant growth promoting characteristic of Mesorhizobium species isolated from chickpea (Cicer arietinum L.) growing areas Ethiopia. Afr. J. Biotechnol., 11(29): 7483-93.

Johnson, J.M., Alex, T. and Oelmuller, R. (2014). Piriformospora indica: The versatile and multifunctional root endophytic fungus for enhanced yield and tolerance to biotic and abiotic stress in crop plants. J. Trop. Agric., 52 (2): 103-122,

Kaur, N. and Sharma, P. (2013). Screening and characterization of native Pseudomonas sp. as plant growth promoting rhizobacteria in chickpea (Cicer arietinum L.) rhizosphere. Afr. J. Microbiol. Res., 7: 1465-1474.

Kumar, M., Yadav, V., Tuteja, N. and Johri, A. (2009). Antioxidant enzyme activities in maize plants colonized with Piriformospora indica. Microbiol., 155: 780-90.

Lakshman, H.C. and Kadam, M.A. (2011). Influence of
AMF and Rhizobium on the growth and nutrient uptake of Lens esculenta. Biosci. Disc., 2(2): 256-60.

Leveau, J.H.J. and Preston, G.M. (2008). Tansley review: bacterial mycophagy: definition and diagnosis of a unique bacterial-fungal interaction. New Phytol., 177: 859-76.

Mamatha, G., Bagyaraj, D.J. and Jaganath, S. (2002). Inoculation of field-established mulberry and papaya with arbuscular mycorrhizal fungi and a mycorrhiza helper bacterium. Mycorrhiza, 12: 313-16.

Marklund, S. and Marklund, G. (1974). Involvement of the Superoxide anion radical in auto-oxidation of pyragallol and a convenient assay for superoxide dismutase. Eur. J. Biochem., 47: 469-74.

Meena, K., Mesapogu, S. Kumar, M., Yandigeri, M.S., Singh, G. and Saxena, A.K. (2010). Co-inoculation of the endophytic fungus Piriformospora indica with the phosphate-solubilising bacterium Pseudomonas striata affects population dynamics and plant growth in chickpea. Biol. Fertil. Soils, 46: 169-74.

Mhadhbi, H., Jebara, M., Limam, F. and Aauani (2004). Rhizobial strain involvement in plant growth, nodule protein composition and antioxidant enzyme activities of chickpea-rhizobia symbiosis: modulation by salt stress. Plant Physiol. Biochem., 42: 717-22.

Mishra, P.K., Bisht, S.C., Jeevanandan, K, Kumar S., Bisht, J.K. and Jagdish Chandra Bhatt, J.C. (2014). Synergistic effect of inoculating plant growthpromoting Pseudomonas spp. and Rhizobium leguminosarum- FB1 on growth and nutrient uptake of rajmash (Phaseolus vulgaris L. Archives of Agronomy and Soil Science. 60: 799-815 DOI:10.1080/ 03650340.2013.843773.

Murphy, B.R., Hodkinson, T.H. and Doohan F.M. (2013). Mechanism of beneficial colonization of barley fungal root endophytes. Aspects Appl. Biol., 120: 35-44.

Moore, S. and Stein, W.H. (1948). Methods in Enzymology. Academic press, New York, pp 68.

Oberwinkler, F., Riess, K., Bauer, R., Selosse, M.A., Weiss, M., Garnica, S. and Zucaro, A. (2013). Enigmatic Sebacinales. Mycological Progress, 12:1-27.

Oelmuller, R., Sherameti, I., Tripathi, S. and Varma, A. (2009). Piriformospora indica, cultivable root endophyte with multiple biotechnological applications. Symbiosis, 49: 1-17.

Parmar, N. and Dadarwal, K.R. (1999). Stimulation of nitrogen fixation and induction of flavonoid like compounds by rhizobacteria. J. Appl. Microbiol., 86: 36-44.

Phillips, J.M. and Hayman, D.S. (1970). Improved procedures for clearing roots and staining parasitic and VAMF for rapid assessment of infection. Trans. Br. Mycol. Soc., 55: 158-61.

Prusty, R., Grisafi, P. and Fink, G.R. (2004). The plant hormone indole acetic acid induces invasive growth in Saccharomyces cerevisiae. Proc. Natl. Acad. Sci. USA 101: 4153-57.

Qiang, X., Weiss, M., Kogel, K.H. and Schafer, P. (2014). Piriformospora indica-a mutualistic basidiomycete with an exceptionally large plant host range. Mol. Plant Pathol., DOI: 10.1111/J.1364-3703.2011.00764.

Rai, M., Acharya, D., Singh, A. and Varma, A. (2001). Positive growth response of the medicinal plants Spilanthes calva and Withania somnifera to inoculation by Piriformospora indica in a field trial. Mycorrhiza, 11: 123-28.

Raja, P., Uma, S., Gopal, H. and Govindarajan (2006). Impact of bioinoculants consortium on rice root exudates, biological 
nitrogen fixation and plant growth. J. Biol. Sci., 6(5): 815-23.

Sartipnia, N., Nejad, R.A.K., Babaeizad, V., Nejad, T., Sattari, T., Najafi, F. (2013). Effect of Piriformospora indica on antioxidant enzymes activity of tomato (Lycopersicon esculentum) under lead stress. Int. J. Biosci., 3:55-64.

Sharma, M., Schmid, M., Rothballer, M., Hause, G., Zuccaro, A., Imani, J., Kampfer, P., Domann, E., Schafer, P., Hartmann, A. and Kogel, K.H. (2008). Detection and identification of bacteria intimately associated with fungi of the order Sebacinales. Cell Microbiol., 10(11): 2235-46.

Singh, L.P., Gill, S.S. and Tuteja, N. (2011). Unravelling the role of fungal symbionts in plant abiotic stress tolerance. Plant Signal Behaviour, 6(2): 175-91.

Singh, N.P. (2014). Presented to the All India Coordinated Research Project in Chickpea, Indian Institute of Pulses Research, Kanpur, Project Coordinater's report Volume 25: 3.

Sirrenberg, A., Gobel, C., Grond, S., Czempinski, N., Ratzinger, A., Karlovsky, P., Santos, P., Feussner, I. and Pawlowski, K. (2007). Piriformospora indica affects plant growth by auxin production. Physiologia Plantarum., 131(4): 581-89.

Slaughter, S.J. and Delwiche, L.D. (2010). The Little SAS
Book for Enterprise Guide 4.2. (Cary, NC, USA: SAS Institute, Inc.) (www.sas.com).

Somogyi, M. (1952). Determination of reducing sugars by Nelson-Somogyi method. J. Biol. Chem., 200: 245.

Sun, C., Johnson, J. M., Cai, D., Sheramati, I., Oelmuller, R. and Lou, B. (2010). Piriformospora indica confers draught tolerance in Chinese cabbage leaves by stimulating antioxidant enzymes, the expression of drought related genes and the plastid localized CAS protein. J. Plant Physiol., 167: 1009-17.

Varma, A., Verma, S., Sahay N.S., Britta, B. and Franken, P. (1999). Piriformospora indica-a cultivable plant growth promoting root endophyte with similarities to arbuscular mycorrhizal fungi. Appl. Envir. Microbiol., 65: 2741-44,USA.

Varma, S., Varma, A., Rexer, K.H., Hassel, A., Kost, G., Sarabhoy, A., Bisen, P., Butenhorn, B. and Franken, P. (1998). Piriformospora indica, a new root colonizing fungus. Mycologia., 90: 896-903.

Verma, J.P., Yadav, J., Tiwari, K.N. and Kumar, A. (2013). Effect of indigenous Mesorhizobium spp. and plant growth promoting rhizobacteria on yields and nutrients uptake of chickpea (Cicer arietinum L.) under sustainable agriculture. Ecol. Eng., 51: 282- 286. 